\title{
Local control in 118 consecutive high-risk breast cancer patients treated with breast-conserving therapy
}

\author{
DIRK VORDERMARK ${ }^{1}$, ANDREA LACKENBAUER ${ }^{1}$, JÖRN WULF ${ }^{1,2}$, \\ MATTHIAS GUCKENBERGER ${ }^{1}$ and MICHAEL FLENTJE ${ }^{1}$ \\ ${ }^{1}$ Department of Radiation Oncology, University of Würzburg, Germany; \\ ${ }^{2}$ Department of Radiation Oncology, Lindenhofspital, Bern, Switzerland
}

Received May 8, 2007; Accepted July 30, 2007

\begin{abstract}
Although negative surgical margins are an important prognostic factor in the breast-conserving treatment of breast cancer, the required width of these margins is still under debate. To define the risk of in-breast recurrence in subgroups of patients with a local high-risk situation, local control was evaluated in all patients with close or positive margins treated at one institution between 1995 and 2000. A total of 118 patients $(67 \% \mathrm{~T} 1,30 \% \mathrm{~T} 2,52 \% \mathrm{~N} 0)$ were identified as having had positive or close margins $(\leq 4 \mathrm{~mm})$ at the time of initial surgery. Of these, $65 \%$ had no tumor cells at the initial margin, $35 \%$ had a positive or questionable margin. Re-excisions were performed in $42 \%$. The median (range) whole-breast radiotherapy dose, tumor bed boost dose and total dose were 50 (46.8-56) Gy, 15 (8-20) Gy and 65.8 (54-71) Gy, respectively. Thirty-six percent received adjuvant chemotherapy. Local (in-breast) control was calculated by the Kaplan-Meier method and compared between subgroups. The 5-year local control for the whole group was $94 \%$. The rates for selected subgroups were: <56 years $89.4 \%$ vs. $>56$ years $98.1 \%$ ( $\mathrm{p}=0.073$, univariate analysis); pT1 $95.9 \%$ vs. pT2 $88.6 \%$ (not significant, n.s.); pN0 $96.6 \%$ vs. pN+ $90.8 \%$ (n.s.); initial margin free of tumor cells $95.5 \%$ vs. initial margin involved or questionable $90.7 \%$ (n.s.), no reexcision $96.7 \%$ vs. one or more re-excisions $90.6 \%$ (n.s.); adjuvant chemotherapy $81.7 \%$ vs. no adjuvant chemotherapy $100 \%(\mathrm{p}=0.007)$. We conclude that among patients with close or positive margins, older patients achieved high local control rates with a median tumor-bed boost to $66 \mathrm{~Gy}$. Younger patients and patients who received adjuvant chemotherapy (due to the presence of histopathological risk factors)
\end{abstract}

Correspondence to: Dr Dirk Vordermark, Department of Radiation Oncology, University of Würzburg, Josef-Schneider-Str. 11, 97080 Würzburg, Germany

E-mail: vordermark_d@klinik.uni-wuerzburg.de

Key words: breast cancer, radiotherapy, breast-conserving therapy, margin were at increased risk of in-breast recurrence and should be considered for intensified local treatment.

\section{Introduction}

The surgical resection margin represents an important risk factor for local recurrence in breast cancer treated with breastconserving surgery and post-operative radiotherapy $(1,2)$. Although there is an international consensus that clear margins should be obtained by surgery before the initiation of radiotherapy, the definition of such negative margins varies, due to the different inclusion criteria applied in the randomized trials establishing the standard of breast-conserving therapy (3-7). In a recent international survey of 1133 radiation oncologists, the definition of 'no tumor cell at the margin' was considered an adequate description of a 'negative margin' by $46 \%$ of North Americans, but only $28 \%$ of Europeans, whereas the most frequently chosen definition among European radiation oncologists was 'no tumor cell within $5 \mathrm{~mm}$ of the margin' (8). The national treatment guideline of the German Cancer Society calls for a margin of $1 \mathrm{~mm}$ or more from the invasive or intraductal tumor component (9).

To elucidate the risk of in-breast recurrence in subgroups of patients with initially close or positive margins, with or without re-excision, we performed a retrospective analysis of local control in 118 consecutive women with a high-risk post-operative margin status.

\section{Materials and methods}

Patients and treatment. The database of all breast cancer patients treated with a breast-conserving approach at the Department of Radiation Oncology, University of Würzburg, Germany, between 1995 and 2000 was searched for those patients in whom 'close margins' or 'positive margins', regarding invasive carcinoma cells, were documented for the initial surgical procedure. In 47 of 118 patients (39.8\%) thus registered, the margin of the initial resection was stated in $\mathrm{mm}$. In these, the margin was always $\leq 4 \mathrm{~mm}(\leq 2 \mathrm{~mm}$ in 43 of 47). The remaining patients were classified by the pathologists as having had 'close', 'very close' or 'positive' margins without a statement regarding the exact margin width. In cases where the surgical and pathology reports (including those of re-resection) did not permit us to judge whether 
Table I. Patients characteristics of $n=118$ patients treated with breast-conserving therapy.

\begin{tabular}{lr}
\hline Mean \pm SD age (range) & $56 \pm 12$ years (28-88) \\
T stage & \\
T1 & $67 \%$ \\
T2 & $30 \%$ \\
T3 & $1 \%$ \\
T4 & $2 \%$ \\
N stage & \\
N0 & $52 \%$ \\
N1 & $36 \%$ \\
N2 & $4 \%$ \\
Nx & $8 \%$ \\
Grading & \\
G1 & $3 \%$ \\
G2 & $58 \%$ \\
G3 & $24 \%$ \\
n.a. & $15 \%$ \\
Estrogen receptor & \\
Positive & \\
Negative & \\
Initial surgical margin status & $67 \%$ \\
No tumor cells at margin & $33 \%$ \\
Margin involved/questionable & \\
Initial surgical margin & \\
width, median (range) & $35 \%$ \\
Final surgical margin & \\
(including reexcision) & \\
No tumor cells at margin & \\
Margin involved questionable & \\
Number of reexcisions & \\
None & \\
One & \\
Two & \\
\hline
\end{tabular}

there were actually tumor cells at the resection margin, the status was considered 'questionable'. The $\mathrm{n}=118$ patients thus identified represent $12.1 \%$ out of a total number of 968 patients treated with radiotherapy as part of a breastconserving approach during the respective time period. Clinical charts of the radiation oncology and gynecology departments, including surgical and pathology reports, were reviewed for patient and treatment characteristics.

Patient characteristics of the $n=118$ consecutive patients fulfilling the above criteria are given in Table I. Treatment characteristics are listed in Table II. The median total dose to
Table II. Treatment characteristics of $\mathrm{n}=118$ patients treated with breast-conserving therapy.

Total RT dose whole breast, 50 (46.8-56) Gy median (range)

Boost technique

Electrons

Interstitial brachytherapy

Total RT boost dose,

15 (8-20) Gy

median (range)

Cumulative total RT dose,

65.8 (54-71) Gy

median (range)

Chemotherapy

$\mathrm{CMF}$

$20 \%$

$\mathrm{EC}$

Hormonal therapy

Tamoxifen

$50 \%$

Other

the whole breast was 50 (46.8-56) Gy. Tangential photon techniques were used, the predominant photon energies were $5 \mathrm{MV}(38 \%)$ and $10 \mathrm{MV}(53 \%)$. Fraction doses were $1.8 \mathrm{~Gy}$ $(14 \%)$ or 2 Gy $(86 \%)$. The median total boost dose was 15 (8-20) Gy, in $95 \%$ of patients given via electrons, resulting in a median total dose of 65.8 (54-71) Gy. A total dose of 6070 Gy was received by $93.2 \%$ of patients. Thirty-six percent of patients received chemotherapy, 59\% hormonal therapy. The mean follow-up interval was $6.6 \pm 1.4$ years.

Statistical analyses. To determine the rate of in-breast recurrence, follow-up notes in these charts were reviewed and treating gynecologists and general physicians were contacted. In cases of known or suspected in-breast recurrences, detailed information including mammograms and further surgical and pathology reports was reviewed.

Local control was calculated for the whole group and subgroups according to the Kaplan-Meier method. In-breast recurrence was considered an event. Patients who died without in-breast recurrence or were alive without in-breast recurrence were censored at the respective time interval. Local control of subgroups was compared by Wilcoxon rank test. Selected parameters were tested in a multivariate Cox regression model. Patients consented to anonymous data analysis as part of the treatment contract with the university hospital.

\section{Results}

A total of eight in-breast recurrences were observed, resulting in a crude local control rate of $93.2 \%$. The actuarial 5-year local control rate, according to Kaplan-Meier, was $94 \%$. When subgroups according to patient or treatment charac- 
Table III. Local control in subgroups of patients with highrisk breast cancer.

Parameter $\begin{array}{ll}\text { 5-year local p-value } \\ \text { control }(\%)\end{array}$

Age (years)
$\leq 56$
$>56$

89.4

0.073

T stage

pT1

95.9

0.16

pT2

88.6

$\mathrm{N}$ stage

pNO

96.6

$\mathrm{pN}+$

90.8

Grading

G2

93.6

G3

89.5

Initial margin

No tumor cells at margin

Final margin

No tumor cells at margin

Involved/questionable

91.8

Estrogen receptor

Positive

93.8

Negative

94.6

Re-excision

None

96.7

90.6

One or more

Total RT dose (Gy)

$\leq 60$

96.5

Adjuvant chemotherapy

Yes

No

Adjuvant hormonal therapy

\begin{tabular}{lll} 
Yes & 93.7 & 0.4 \\
No & 94.4 & \\
\hline
\end{tabular}

teristics were compared (Table III), only the administration of adjuvant chemotherapy was associated with significantly increased local recurrence rates on univariate analysis (Fig. 1). Younger patients ( $<56$ years) also had higher local recurrence rates (Fig. 2), this finding was of borderline

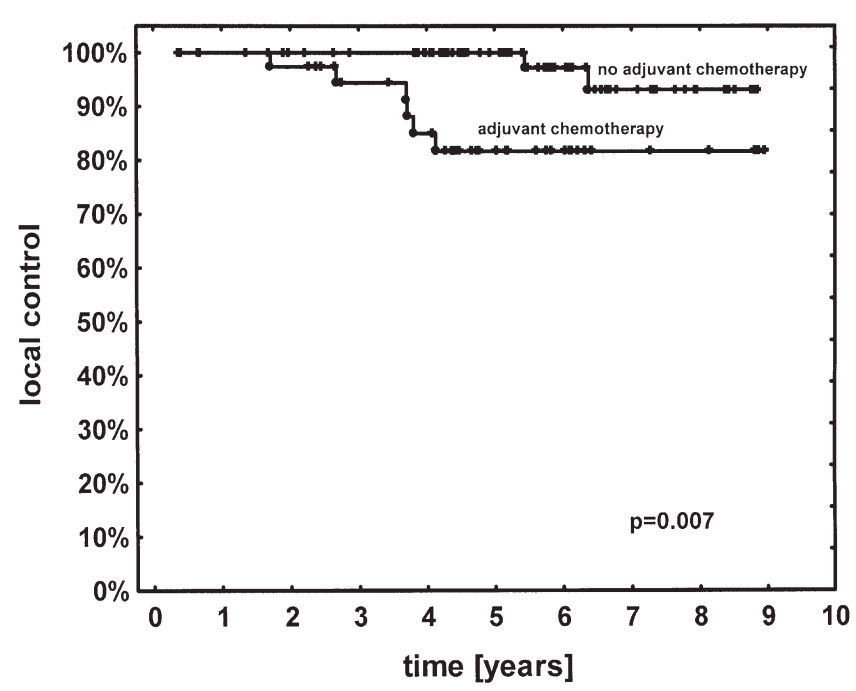

Figure 1. Local control according to administration of adjuvant chemotherapy.

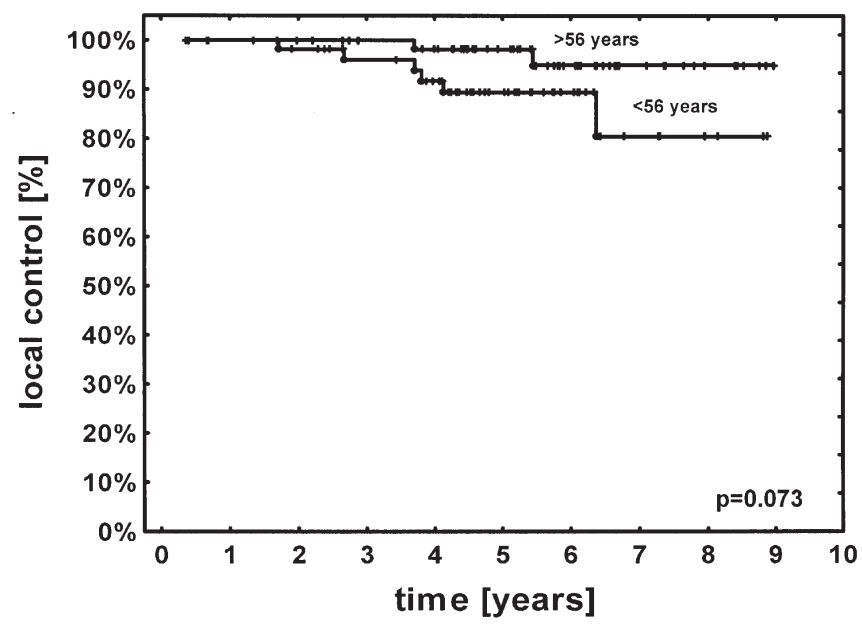

Figure 2. Local control according to age group.

significance $(\mathrm{p}=0.073)$. Lower local control rates were also seen in patients with other prognostic factors (higher $\mathrm{T}$ or $\mathrm{N}$ stage, higher grading, higher radiotherapy dose) but these differences were not significant.

When the two parameters with $\mathrm{p}<0.1$ were entered into a multivariate Cox model, administration of chemotherapy remained of borderline significance $(\mathrm{p}=0.062)$ whereas age lost significance $(\mathrm{p}=0.63)$. In a model with these parameters and the known risk factors total RT dose, final resection margin and $\mathrm{T}$ stage, the administration of chemotherapy $(\mathrm{p}=0.11)$ and the other factors were not significant.

\section{Discussion}

In the present analysis of in-breast tumor control after breastconserving treatment in patients registered as having had 'close' or 'positive' margins, a rather low local recurrence rate of $6 \%$ at five years was observed. Obviously, the low number of events in this six-year experience from a high- 
volume university department represents a limitation of statistical analysis of prognostic factors for in-breast control. In subgroup analyses, only the administration of adjuvant chemotherapy was linked, on univariate analysis, to a significantly increased local recurrence rate of $18.3 \%$ at five years. Interestingly, not a single in-breast recurrence was observed after five years in patients not receiving adjuvant chemotherapy. This association of local control and chemotherapy administration was lost on multivariate analysis and is, therefore, most likely due to the selection of patients for adjuvant chemotherapy who had a combination of risk factors such as higher $\mathrm{T}$ stage, higher $\mathrm{N}$ stage, higher grading, younger age and negative estrogen receptor status. Except for estrogen receptor status, each of these factors alone was associated with a slightly, but not significantly, lower local control rate. The association of younger age ( $<56$ years) alone with local control was of borderline significance on univariate analysis $(\mathrm{p}=0.073)$.

In the time period under investigation, the local policy for radiotherapy after breast-conserving surgery was to give 50 Gy whole-breast and 10 Gy boost radiotherapy to patients with wide negative margins and 50 plus 16 Gy boost to patients with close or positive margins. There was, however, no fixed limit in mm to define 'close' margins and definitions of close or negative margins have not been uniformly applied in the international literature (8). For the purpose of the present analysis, only patients with margins described in the pathology report as involved, 'close' or 'very close' or were included. In the cases where margin width was stated in $\mathrm{mm}$, this was always $\leq 4 \mathrm{~mm}$, mostly $\leq 2 \mathrm{~mm}$.

To compare the present results with published data, it must be considered that the majority of the 'high-risk' patients analyzed now would have been regarded as standard risk in some clinical trials in which only the absence of invasive carcinoma at the inked margin was required. This was the case in the EORTC 'boost vs. no boost' trial in which patients were randomized to receive a 16-Gy boost or no boost to the tumor bed after 50 Gy of whole-breast therapy (10). In the two arms of that trial, the re-excision rate was about $25 \%$ compared to $42 \%$ in the present series. In the boost arm, the total dose of which is comparable to the mean total dose of this series, the 5-year local control rate was $95.7 \%$, with a strong age dependence ( $\leq 40$ years: $89.8 \%, 41-50$ years: $94.2 \%, 51-60$ years: $96.6 \%, \geq 61$ years: $97.5 \%$ ). In the present series, where age groups were split at the median of 56 years, local control was similar to the EORTC data for the older group (98.1\% at five years) but apparently worse for the under-56-year-olds $(89.4 \%)$. This suggests that the margin status is especially critical in younger patients, whereas a boost dose of approximately 16 Gy can compensate for close margins in older patients.

Other authors have published the outcome of a strict 'margin-directed' policy in 498 patients, where boost doses were $10 \mathrm{~Gy}$ (margin $>5 \mathrm{~mm}), 14 \mathrm{~Gy}(2-5 \mathrm{~mm})$ or $20 \mathrm{~Gy}$ (positive or $<2 \mathrm{~mm}$ ) (11). In case of a re-excision showing no residual tumor no boost was given. With this approach, 12-year local control rates were $83 \%$ (positive margin), $91 \%$ (margin $>0 \mathrm{~mm}$ to $2 \mathrm{~mm}$ ), $95 \%(2-5 \mathrm{~mm}), 100 \%$ (>5 mm) and $94 \%$ (re-excision without residual tumor). These data confirm that increased boost doses cannot generally compensate for positive or very close margins but also suggest that a negative histology on re-excision is not equivalent to initially wide negative margins.

In another recent analysis, the six-year local control after predominantly $50 \pm 10 \mathrm{~Gy}$ in 535 patients was $97 \%$ in patients with negative ( $>2 \mathrm{~mm}$ ) margins, but $83 \%, 78 \%$ and $15 \%$ in patients with positive, close $(\leq 2 \mathrm{~mm})$ or indeterminate margins, respectively, emphasizing the recurrence risk associated with close or uncertain margin status in the context of standard boost doses (12).

Within our study cohort, young age is the one pre-treatment factor most strongly linked to poor local control. A subsequent analysis of the above-mentioned EORTC trial showed that young age was correlated with a higher prevalence of adverse prognostic factors (tumor size, grading, receptor status, initial incomplete resection in order to preserve the breast) but that only young age and radiotherapy dose remained significant in a multivariate analysis (13). The authors suggested, that the worse local control in younger patients might be explained by a different biologic and genetic background of these tumors. Molecur markers and gene expression profiling approaches to predict the probability of distant metastasis in individual breast cancer patients have been developed (14-16) and more recently the estimation of the local recurrence risk has been addressed in such studies (17). For patients 50 years or younger, an international randomized trial comparing boost doses of 16 and 26 Gy is currently recruiting patients (18).

In conclusion, a satisfactory local control rate of $94 \%$ at five years was achieved in 118 consecutive patients with close, uncertain or positive margins applying a mean total dose of 66 Gy. However, patients in whom adjuvant chemotherapy was administered and patients under 56 years of age achieved local control at five years only in 81.7 and $89.4 \%$, respectively, suggesting that intensified local treatment should be considered in subgroups of patients with close or positive margins.

\section{References}

1. Singletary SE: Surgical margins in patients with early-stage breast cancer treated with breast conservation therapy. Am J Surg 184: 383-393, 2002.

2. Pomp J, Blom J, Zwinderman AH, Sastrowijoto SH and van Krimpen C: Analysis of local recurrence after breast conservative treatment for invasive breast cancer: a single institution cohort. Oncol Rep 14: 1255-1261, 2005.

3. Fisher B, Anderson S, Bryant J, Margolese RG, Deutsch M, Fisher ER, Jeong JH and Wolmark N: Twenty-year follow-up of a randomized trial comparing total mastectomy, lumpectomy, and lumpectomy plus irradiation for the treatment of invasive breast cancer. N Engl J Med 347: 1233-1241, 2002.

4. Jacobson J, Danforth D, Cowan K, D'Angelo T, Steinberg S, Pierce L, Lippmann ME, Lichter AS, Glatstein E and Okunieff P: Ten-year results of the National Cancer Institute's randomized trial of breast conservation versus mastectomy for stage I and II breast cancer. N Engl J Med 332: 907-911, 1995.

5. Van Dongen J, Voogd AC, Fentiman IS, Legrand C, Sylvester RJ, Tong D, van der Schueren E, Helle PA, van Zijl K and Bartelink H: Long-term results of a randomized trial comparing breast-conserving therapy with mastectomy: European Organization for for Research and Treatment of Cancer 10801 trial. J Natl Cancer Inst 92: 1143-1150, 2000.

6. Arriagada R, Le MG, Rochard F and Contesso G: Conservative treatment versus mastectomy in early breast cancer: patterns of failure with fifteen years of follow-up. J Clin Oncol 14: 1558-1564, 1996. 
7. Veronesi U, Cascinelli N, Mariani L, Greco M, Saccorizzi R, Luini A, Aguilar M and Marubini E: Twenty-year follow-up of a randomized study comparing breast-conserving surgery with radical mastectomy for early breast cancer. N Engl J Med 347: 1227-1232, 2002.

8. Taghian A, Mohiuddin M, Jagsi R, Goldberg S, Ceilley E and Powell S: Current perceptions regarding surgical margin status after breast-conserving therapy. Results of a survery. Ann Surg 241: 629-639, 2005.

9. Kreienberg R, Kopp I, Lorenz W, Budach W, Dunst J, Lebeau A, Lück H-J, v. Minckwitz G, Possinger K, Sauerbrei W, Sauerland S, Souchon R, Thomssen C, Untch M, Volm T, Weis J, Schmitt-Reisser B, Koller M, Heilmann V: Diagnostik, Therapie und Nachsorge des Mammakarzinoms der Frau. Eine nationale S3-Leitlinie. Deutsche Krebsgesellschaft (ed): ISTO, Frankfurt, 2004.

10. Bartelink H, Horiot JC, Poortmans P, Struikmans H, van den Bogaert W, Barillot I, Fourquet A, Borger J, Jager J, Hoogenraad W, Collette L and Pierart M: Recurrence rates after treatment of breast cancer with standard radiotherapy with or without additional radiation. N Eng J Med 345: 1378-1387, 2001.

11. Neuschatz AC, Di Petrillo T, Safaii H, Lyn Price L, SchmittUllrich RK and Wazer DE: Long-term follow-up of a prospective policy of margin-directed radiation dose escalation in breastconserving therapy. Cancer 97: 30-39, 2003.

12. Smitt MC, Nowels K, Carlson RW and Jeffrey SS: Predictors of reexcision findings and recurrence after breast conservation. Int J Radiat Oncol Biol Phys 57: 979-985, 2003.
13. Vrieling C, Collette L, Fourquet A, Hoogenraad WJ, Horiot JC, Jager JJ, Oei SB, Peterse HL, Pierart M, Poortmans PM, Struikmans H, van den Bogaert W and Bartelink H: Can patient-, treatment- and pathology-related characteristics explain the high local recurrence rate following breast-conserving therapy in young patients? Eur J Cancer 39: 932-944, 2003.

14. Van't Veer L, Dai H, van der Vijver MJ, He YD, Hart AA, Mao M, Peterse HL, van der Kooy K, Marton MJ, Witteveen AT, Schreiber GJ, Kerkhoven RM, Roberts C, Linsley PS, Bernards R and Friend SH: Gene expression profiling predicts clinical outcome of breast cancer. Nature 415: 530-536, 2002.

15. Varangot M, Barrios E, Sonora C, Aizen B, Pressa C, Estrugo R, Lavigna R, Muse I, Osinaga E and Berois N: Clinical evaluation of a panel of mRNA markers in the detection of disseminated tumor cells in patients with operable breast cancer. Oncol Rep 14: 537-545, 2005.

16. Zhu L, Loo WT, Cheng CW and Chow LW: Possible predictive markers related to micro-metastasis in breast cancer patients. Oncol Rep 15: 1217-1223, 2006.

17. Nuyten DS, Kreike B, Hart AA, Chi JT, Sneddon JB, Wessels LF, Peterse HJ, Bartelink H, Brown PO, Chang HY and van de Vijver MJ: Predicting a local recurrence after breast-conserving therapy by gene expression profiling. Breast Cancer Res 8: R62, 2006.

18. Bartelink H, Boersma LJ, Leer JW and Poortmans P: Radiation dose intensity study in breast cancer in young women: a randomized phase III trial of additional dose to the tumor bed. Netherlands Cancer Institute, Amsterdam, 2004 (ClinicalTrials. gov identifier NCT00212121). 